\title{
Effects of age on performance in a finger-precuing task
}

Citation for published version (APA):

Adam, J. J., Paas, F. G. W. C., Teeken, J. C., van Loon, E. M., van Boxtel, M. P. J., Houx, P. J., \& Jolles, J. (1998). Effects of age on performance in a finger-precuing task. Journal of Experimental PsychologyHuman Perception and Performance, 24(3), 870-883. https://doi.org/10.1037/0096-1523.24.3.870

Document status and date:

Published: 01/01/1998

DOI:

10.1037/0096-1523.24.3.870

Document Version:

Publisher's PDF, also known as Version of record

\section{Please check the document version of this publication:}

- A submitted manuscript is the version of the article upon submission and before peer-review. There can be important differences between the submitted version and the official published version of record.

People interested in the research are advised to contact the author for the final version of the publication, or visit the DOI to the publisher's website.

- The final author version and the galley proof are versions of the publication after peer review.

- The final published version features the final layout of the paper including the volume, issue and page numbers.

Link to publication

\footnotetext{
General rights rights.

- You may freely distribute the URL identifying the publication in the public portal. please follow below link for the End User Agreement:

www.umlib.nl/taverne-license

Take down policy

If you believe that this document breaches copyright please contact us at:

repository@maastrichtuniversity.nl

providing details and we will investigate your claim.
}

Copyright and moral rights for the publications made accessible in the public portal are retained by the authors and/or other copyright owners and it is a condition of accessing publications that users recognise and abide by the legal requirements associated with these

- Users may download and print one copy of any publication from the public portal for the purpose of private study or research.

- You may not further distribute the material or use it for any profit-making activity or commercial gain

If the publication is distributed under the terms of Article $25 \mathrm{fa}$ of the Dutch Copyright Act, indicated by the "Taverne" license above, 


\title{
Effects of Age on Performance in a Finger-Precuing Task
}

\author{
Jos J. Adam, Fred G. W. C. Paas, Joep C. Teeken, Editha M. van Loon, \\ Martin P. J. van Boxtel, Peter J. Houx, and Jelle Jolles \\ Maastricht University
}

\begin{abstract}
This study investigated age-related precuing effects in the finger-precuing task (J. Miller, 1982). In this task, a spatial precue provides partial advance information about which fingers to use for responding. Results indicated a substantial age-related deficit in preparing 2 fingers on 2 hands, but not on 1 hand. This disparate set of findings does not provide strong support for A. A. Hartley's (1993) hypothesis that anterior brain attention systems responsible for selection-for-action are compromised with advancing age. Finally, the authors report that advancing age increasingly slows reaction time more to the inner than to the outer stimulus-response positions. A possible mechanism of this age-related bowed stimulusresponse position effect is discussed.
\end{abstract}

Spatial-precuing effects have been studied extensively in the last two decades. In general, spatial-precuing effects refer to the finding that precuing the location of a to-bepresented target stimulus enhances its subsequent processing, as evidenced by substantial improvements in response speed and response accuracy. It is commonly agreed that the underlying mechanism is a shift of attention; that is, the spatial precue directs attention to the probable location and thereby enables perceptual processing resources to be allocated to the most relevant source of information (e.g., Eriksen, 1990; Posner, 1980; Shiffrin, 1988). Generally, precuing benefits in perceptual tasks are not negatively affected by advancing age, a finding consistent with the concept of selective preservation of selective attention in later adulthood (for a review see Madden \& Plude, 1993).

The goal of our research was to determine age-related

Jos J. Adam, Joep C. Teeken, and Editha M. van Loon, Department of Movement Sciences, Maastricht University, Maastricht, The Netherlands; Fred G. W. C. Paas and Peter J. Houx, Department of Psychology, Maastricht University, Maastricht, The Netherlands; Martin P. J. van Boxtel, Department of Psychiatry and Neuropsychology, Maastricht University, Maastricht, The Netherlands; Jelle Jolles, Departments of Psychology and of Psychiatry and Neuropsychology, Maastricht University, Maastricht, The Netherlands.

This work was supported by a grant from the Dutch Ministries of Education and Health and Welfare through the Steering Committee for Gerontological Research (Nestor) and was conducted as part of the Maastricht Aging Study (Jolles, Houx, van Boxtel, \& Ponds, 1995). A parallel study, which used the same participants that we used in Experiment 1, examined the effects of age on discrete and reciprocal aiming movements (see Teeken, Adam, Paas, van Boxtel, Houx, \& Jolles, 1996).

We thank Astrid Quist for her extensive help in the data collection and Robert Proctor, David Rosenbaum, and an anonymous reviewer for helpful comments on an earlier version of the manuscript.

Correspondence concerning this article should be addressed to Jos J. Adam, Department of Movement Sciences, Maastricht University, P.O. Box 616, 6200 MD Maastricht, The Netherlands. Electronic mail may be sent to jos.adam@bw.unimaas.nl. precuing effects in a specific variant of the spatial-precuing technique, namely, the spatial finger-precuing task, developed by Miller (1982). In the finger-precuing task, a spatial precue provides information about which fingers to use for responding. This finger-precuing task differs from the more traditional spatial-precuing tasks involving target detection (Bashinski \& Bacharach, 1980; Posner, Snyder, \& Davidson, 1980; van der Heijden \& Eerland, 1973), target identification (e.g., Eriksen \& Rohrbaugh, 1970; Hoffman, 1975; van der Heijden, Schreuder, \& Wolters, 1985), and target discrimination (e.g., Cheal \& Lyon, 1991; Henderson, 1991; Lyon, 1990) in that both perceptual, and more prominently, postperceptual processes (i.e., processes concerned with response selection and response preparation) mediate task performance. ${ }^{1}$

Applying the finger-precuing task to the study of cognitive aging was considered relevant for evaluating Hartley's (1993) proposal that age-related differences are large when (attentional) performance depends on selecting one category of processing and ignoring others (i.e., selection-for-action), whereas age differences are relatively small when performance depends on selecting a specified location in visual space and ignoring others (i.e., selection-for-perception). The latter part of this claim is, in part, based on the above-mentioned evidence that age differences are usually small or absent in perceptual precuing tasks. For example, Hartley, Kieley, and Slabach (1990) found no age difference in costs and benefits of spatial cues. Furthermore, younger and older adults seem equally able to broaden or narrow the focus of attention (Hartley, Kieley, \& McKenzie, 1992; Hartley \& McKenzie, 1991). In contrast, when attention must be directed to two different tasks, age differences are

\footnotetext{
${ }^{1}$ By postperceptual we mean the set of processing operations that intervene after the cue is identified and before the response is executed, that is, the selection of the responses associated with the cue and the planning or programming of the relevant motor output (e.g., Rosenbaum, 1983). Note that although some authors equate response selection with stimulus-response translation (e.g., Proctor \& Reeve, 1988), others do not (e.g., Umiltá \& Nicoletti, 1990). This issue, however, is not relevant for the present study.
} 
characteristically large (for reviews see Madden \& Plude, 1993; McDowd \& Birren, 1990). Moreover, age differences are also large on the Stroop task, in which the word name and color name compete for response output (e.g., Spieler, Balota, \& Faust, 1996).

Hartley (1993) has argued that his hypothesis is consistent with the notion that there are at least two distinct attention systems in the human brain, the posterior attention system and the anterior attention system, a notion supported by a large body of evidence from the neurosciences and neuropsychology (e.g., Brown, 1996; Carr, 1992; Goldberg \& Segraves, 1987; Posner \& Petersen, 1990; Shallice, 1988). The posterior attention system involves the parietal cortex and superior colliculus. Its main function is directing and focusing attention on a specific location in visual space. Spatial neglect, a failure to attend to objects in one part of space, can result from damage to the parietal lobes (e.g., Heilman, Watson, \& Valenstein, 1985). The anterior attention system consists primarily of frontal lobe structures, including the motor cortex. Its main function is selecting one of several possible categories of processing or action. For example, performance on the Stroop task in which participants must select one category of processing and inhibit another is commonly impaired in individuals with damage to the frontal lobes (e.g., Craik, Morris, Morris, \& Loewen, 1990). Therefore, according to Hartley (1993), an agerelated dissociation in performance on selection-forperception and selection-for-action tasks is neuropsychologically plausible. ${ }^{2}$ In sum, Hartley proposed that age-related differences in attentional performance will be found (primarily) in selection-for-action tasks (i.e., tasks subserved by anterior attentional systems). By contrast, Hartley suggested that selection-for-perception tasks (i.e., tasks subserved by posterior brain systems) will show relatively small agerelated differences.

We tested the first part of Hartley's proposal. Because the finger-precuing task, in contrast to perceptual-precuing tasks, substantially taps selection-for-action processes (governed by the operation of anterior brain attention systems), finger-precuing benefits should, according to Hartley's proposal, be adversely affected in older adults. Note that our test concerned the psychological hypothesis rather than the physiological speculation that motivated it (see also Hartley, 1993).

\section{Spatial-Precuing Effects}

In a typical spatial-precuing experiment, participants are provided with advance information by means of a precue regarding the spatial location of a target stimulus. The precue can be a centrally presented, symbolic precue (e.g., an arrow) or a locally presented, spatial precue (e.g., a marker or flash of light). Also, often the predictive value of the precue is manipulated; it can be valid (indicating the target location) or invalid (indicating a nontarget location). Valid cues generally produce benefits, and invalid cues generally produce costs. In the present study, we were only concerned with locally presented, valid cues.

Spatial precues are often embedded in tasks requiring visual detection, identification, or discrimination of the target stimulus. Performance in these kinds of tasks critically depends on perceptual processes, and precuing benefits, therefore, have typically been understood in terms of some localized enhancement in perceptual efficiency that is produced by a shift of attention to the precued location.

How does age affect the ability to take advantage of precues? The studies that have addressed the issue of age-related spatial-precuing effects indicate that spatialprecuing benefits are the same (and sometimes even larger) for older adults compared with younger adults (Folk \& Hoyer, 1992; Greenwood, Parasuraman, \& Haxby, 1993; Hartley et al., 1990; Hoyer \& Familant, 1987; Nissen \& Corkin, 1985; Tellinghuisen, Zimba, \& Robin, 1996). As we noted before, however, this conclusion is limited to precuing effects established in perceptual tasks. The present study sought to investigate whether the same finding is true for precuing benefits that incorporate processes concerned with response selection and response preparation. To this end, we used the finger-precuing task.

\section{The Finger-Precuing Task}

Miller's (1982) finger-precuing task, which is a modified version of the movement precuing technique developed by Rosenbaum $(1980,1983)$, requires participants to respond to spatial-location stimuli with discrete responses from index and middle fingers of both hands. Typically, the hands are placed adjacently. The display consists of three horizontal rows, representing warning, precue, and target stimulus, respectively. The warning stimulus consists of four plus ( + ) signs, indicating the four possible stimulus locations. The precue consists of two plus signs, indicating two possible stimulus locations. The target stimulus consists of one plus sign, indicating the target stimulus location. The temporal order of these three rows is as follows: First, the waming stimulus is presented, then, after a delay that is typically constant, the precue is presented, and then, after a delay that is typically variable, the target stimulus is presented. The variable delay is called the preparation interval, as it reflects the amount of time participants are given to selectively prepare the two finger responses indicated by the precue, before the imperative target stimulus is presented. In other words, the functional significance of the precue is that it transforms the original four-choice reaction task into a two-choice reaction task.

\footnotetext{
${ }^{2}$ Note that a distinction between selection-for-perception and selection-for-action attentional mechanisms is also prominently present in the work of, for example, Allport (1987), Pashler (1991), Schneider (1995), and Shallice (1988). An important point to note is that on the basis of a review of neurophysiological evidence, Goldberg and Segraves (1987) explicitly suggested the name motor attention to emphasize its similarity with the process of visuospatial attention. That is, by analogy with the selection process in the visuospatial domain, they postulated that the process of motor attention involves a choice among competing internal motor signals rather than among conflicting external stimuli in the environment. They argued that the frontal cortex is important for this motoric selection process.
} 
Four precue conditions can be distinguished in the context of finger precuing. In the hand-cued condition, the precue specifies two fingers on the same hand (e.g., the left-middle and left-index fingers). In the finger-cued condition, the precue specifies the same finger on different hands (e.g., the left-index and right-index fingers). In the neither-cued condition, the precue specifies different fingers on different hands (e.g., the left-middle and right-index fingers). Also, an uncued condition is included in which the precue provides no advance information (it contains plus signs in all four possible stimulus locations) and thus precludes selective preparation of any combination of two-finger responses. The uncued condition is a control condition because it leaves the basic, four-choice reaction task unaltered. Because the Hick-Hyman law (Hick, 1952; Hyman, 1953) states that a two-choice reaction task results in shorter reaction times (RTs) than a four-choice reaction task, precue effectiveness is inferred from a significant RT benefit for the two-choice precue conditions (i.e., hand-cued, finger-cued, and neither-cued) relative to the control, four-choice uncued condition. In Figure 1, the finger-precuing task is presented schematically.

A robust finding from the finger-precuing task is a pattern of differential precuing benefits (for a review, see Reeve \& Proctor, 1990). RTs are shortest for the hand-cued condition and longest for the neither-cued condition, with the fingercued condition being intermediate. This pattern of differential precuing benefits is apparent primarily at short preparation intervals (intervals less than $1,500 \mathrm{~ms}$ ). When the preparation interval is extended to $3 \mathrm{~s}$, all three precue conditions show similar RTs. Thus, certain pairs of responses can be selected and prepared more quickly than others, with no differences between the pairs once the responses have been selected and prepared.

It is important to note that the time course of fingerprecuing benefits is in sharp contrast with the time course of precuing benefits in perceptual tasks requiring detection, identification, and discrimination. In the latter case, precuing benefits accrue extremely quickly (the biggest gains typically occur within the first 50 to $100 \mathrm{~ms}$ ) and usually reach asymptotic values within $200 \mathrm{~ms}$ of precuing time (for a review, see Eriksen, 1990). Consequently, the fact that relatively long preparation intervals in the finger-precuing task are needed to achieve maximal precuing benefits implicates a postperceptual locus of finger-precuing ben-

\section{FINGER PRECUING PARADIGM}

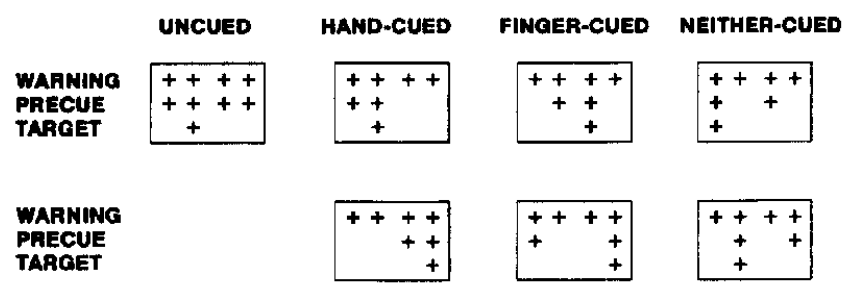

Figure 1. A schematic representation of the finger-precuing paradigm as developed by Miller (1982). efits. In addition, psychophysiological studies have provided direct evidence that precuing effects reside, at least partially, in the (pre)motor cortex (e.g., de Jong, Wierda, Mulder, \& Mulder, 1988; Leuthold, Sommer, \& Ulrich, 1996; Requin, Riehle, \& Seal, 1993). In summary, there is widespread consensus that precuing benefits in the finger-precuing task are mediated by postperceptual processes concerned with response selection and response preparation (Adam, 1994; Miller, 1982, 1985; Reeve \& Proctor, 1984, 1985, 1990; Requin, Brener, \& Ring, 1991; Rosenbaum, 1983). In view of this consensus, we decided to examine the nature of finger precuing as a function of age.

\section{Purpose of the Study}

Recent evidence suggests that older and younger adults perform about equally well on a wide variety of spatialprecuing tasks. Mainly, however, these tasks have used spatial precues that facilitated perceptual processes involved in target detection, identification, and discrimination. By adopting the finger-precuing task (Miller, 1982), in the present study, we investigated age-related postperceptual precuing effects. If, as Hartley (1993) proposed, age-related differences are large when performance depends on selectionfor-action, then substantial finger-precuing deficits as a function of advancing age should materialize.

\section{Experiment 1}

In the first experiment, we examined precuing benefits in the hand-cued condition relative to the uncued condition, following a short (i.e., $100 \mathrm{~ms}$ ) and long (i.e., 2,000 ms) preparation interval. Additionally, and in contrast to most aging studies that compare performance of relatively young participants (typically between 20 and 25 years of age) with that of relatively old participants (typically between 60 and 80 years of age), we used six different age groups that spanned the entire age range: $25,35,45,55,65$, and $75( \pm 1)$ years of age, a method that allowed a closer examination of the time course of age-related effects. Finally, in order to gather more detailed information about age-related slowness, we performed an analysis of age-related RT differences as a function of stimulus-response position (Adam \& Van Veggel, 1992).

\section{Method}

Participants. A total of 140 participants ${ }^{3}$ served as volunteers, with ages centered ( \pm 1 year) around $25,35,45,55,65$, and 75 years; the number of men and women in these age groups was $15-10,16-9,14-15,16-10,13-9$, and 6-7, respectively. Participants were recruited by random selection from a register of patients of general practices in the Maastricht region (Metsemakers, Höppener, Knottnerus, Kocken, \& Limonard, 1992). This register contains all relevant past and current medical morbidity as

\footnotetext{
${ }^{3}$ The initial sample contained 141 participants. However, one participant was excluded because of an extremely large error rate (28.1\% errors).
} 
documented by general practitioners. Because health status may confound outcome measures in cognitive aging research (e.g., M. F. Elias, J. W. Elias, \& P. K. Elias, 1990; Houx \& Jolles, 1993), special precautions were taken to include only physically healthy participants. Exclusion criteria were previous or actual medical conditions with known impact on cognitive, motor, or both functions: overt cerebrovascular disease, chronic neurological pathology (e.g., dementia, epilepsy, and parkinsonism), mental retardation, chronic cardiovascular or pulmonary disease, or psychotropic drug use. All participants had normal or corrected-to-normal vision. Except for 3 participants, they all wrote with their right hands. ${ }^{4}$ Informed consent was obtained from all participants.

Data for IQ were collected for all but one participant. IQ was measured by means of a standard Dutch intelligence test (Luteijn \& van der Ploeg, 1983). The different age groups were not reliably different in terms of $\mathrm{IQ}, F(5,133)=1.97, M S E=183.40, p>.05$ $(M s=108.5,114.2,114.0,111.5,110.2,121.9$ for ages 25, 35, 45, 65 , and 75 years, respectively).

Apparatus and stimuli. Stimuli were presented on a standard video display monitor controlled by an IBM-AT computer. Responses were made by pressing one of four keys $(\mathrm{Z}, \mathrm{X}$, ., and $)$ of the keyboard (the two left-most and two right-most keys on the bottom row of the keyboard). Viewing distance was held constant at about $50 \mathrm{~cm}$. The computer was housed in a normally lit room and was used to control the presentations of the stimulus displays and to record response latencies and accuracies.

Stimuli were plus (+) signs presented in the standard character set of the computer; each plus sign was approximately $2.5 \mathrm{~mm}$ wide and $4.5 \mathrm{~mm}$ high. The stimulus display consisted of a warning signal, a cue signal, and a target signal, with the entire display centered on the viewing monitor. The warning signal was a row of four plus signs. Two blank spaces covering $7.6 \mathrm{~mm}$ separated the two left-most, and also the two right-most, positions; the two center positions were separated by four blank spaces covering $15.2 \mathrm{~mm}$. Hence, the gap between the two center positions was larger than the gap between the two left-most and the two right-most positions, creating grouping of the latter pairs by proximity. After a delay of $750 \mathrm{~ms}$, the cue signal appeared immediately below the warning signal. The cue consisted of plus signs either in all four positions indicated by the warning signal (uncued condition) or in only two of the four possible positions (the two left-most or the two right-most positions: the hand-cued condition). After a variable (preparation) interval (i.e., 100 or $2,000 \mathrm{~ms}$ ), the target signal (one single plus sign) appeared immediately below the cue row in a position always indicated by the cue. The participant's task was to respond as quickly as possible to the position in which the target signal occurred by pressing the appropriate response key. Target signal and response key were mapped onto each other in a spatially compatible manner such that a target appearing in the left-most position was to be responded to with the left-middle finger pressing the left-most response key, etc. An intertrial interval of $1 \mathrm{~s}$ separated the response in a trial from the start of the next trial.

Procedure. Two preparation intervals were used (100 and 2,000 ms) and two cue conditions: uncued and hand-cued. Each participant received a block of 80 trials for each preparation interval. A rest period of $3 \mathrm{~min}$ was provided between blocks. Within a block of 80 trials, there were 40 trials for the uncued condition (10 for each of the four stimulus positions) and 40 trials for the hand-cued condition (also 10 for each of the four stimulus positions). The order of these cuing conditions within a block of 80 trials was random. Twenty-five practice trials preceded each block of 80 test trials.
Participants were informed regarding the nature of the task and were explicitly told to take advantage of the cue stimulus. They were instructed to react as quickly as possible to the target stimulus by pressing the correct response key. It was emphasized that participants should not make more than five errors in a block of $\mathbf{8 0}$ trials. Error feedback was provided on individual trials.

Analysis. RTs less than $150 \mathrm{~ms}$ or in excess of $1.5 \mathrm{~s}$ were considered outliers and were excluded from data analyses; less than $0.2 \%$ of the RTs were removed using this criterion. Mean correct RTs and proportions of errors were calculated for each participant as a function of preparation condition, preparation interval, and stimulus-response position. A split-plot, unweighted means analysis of variance (ANOVA) to control for the unequal numbers of participants in the different conditions (Keppel, 1982) was performed on mean RTs and percentage errors, with age as the between-subject variable and preparation condition (uncued and hand-cued), preparation interval (100 and $2,000 \mathrm{~ms}$ ), and stimulusresponse position $(1,2,3 \text {, and } 4)^{5}$ as within-subject variables. Whenever appropriate, we used the Huynh-Feldt corrected signifcance values to adjust the tests involving the within-subject factor(s) for heterogeneity of variance and covariances. We used Tukey's honestly significant procecture to perform post hoc analyses.

\section{Results}

Reaction time. There were significant main effects for age, $F(5,134)=19.06, M S E=67,203.00, p<.001$; preparation condition, $F(1,134)=829.81, M S E=1,830.00$, $p<.001$; preparation interval, $F(1,134)=7.40, M S E=$ $8,424.00, p<.01$; and stimulus-response position, $F(3$, $402)=103.30, M S E=2,509.00, p<.001$. These main effects indicated longer RTs with advancing age (448, 449, $476,523,557$, and $612 \mathrm{~ms}$ for ages $25,35,45,55,65$, and 75 years, respectively), shorter RTs for the hand-cued than for the uncued condition ( 484 and $538 \mathrm{~ms}$, respectively), shorter RTs for preparation interval 100 than for $2,000 \mathrm{~ms}$ (505 and $517 \mathrm{~ms}$, respectively), and an inverted-U shape RT curve as a function of stimulus-response position (503, 522, 536, and $485 \mathrm{~ms}$ for left-to-right positions, respectively). These main effects, however, were qualified by several interactions.

The significant Preparation Condition $\times$ Preparation Interval interaction, $F(1,134)=121.54, M S E=1,549.00$,

${ }^{4}$ This rather low percentage $(2.1 \%)$ of left-handers is probably related to the fact that until quite recently, the Dutch educational system actively encouraged left-handers to write with their right hand. This is in accordance with a recent study by Davis and Annett (1994), who reported a marked and regular decline in the percentage of left-handed writers with increasing age and attributed this finding to a gradual relaxation of pressure against use of the left hand for writing in the course of the twentieth century.

${ }^{5}$ The numbers $1,2,3$, and 4 refer, from left to right, to the first, second, third, and fourth stimulus positions that are associated with the left-middle finger, the left-index finger, the right-index finger, and the right-middle finger, respectively. Because the variable stimulus position is confounded with the variable response finger we thought it would be appropriate to use the term stimulusresponse position rather than either of the terms stimulus position or response finger. 
$p<.001$, indicated that the precuing benefit (i.e., the difference between the uncued and hand-cued condition) was half as large for the $100 \mathrm{~ms}$ as for the $2,000 \mathrm{~ms}$ preparation interval (35 and $73 \mathrm{~ms}$, respectively). This finding is consistent with the notion that finger-precuing benefits need time to develop.

The differential precuing benefit for short- and longpreparation intervals varied as a function of age, as evidenced by a significant three-way Age $\times$ Preparation Condition $\times$ Preparation Interval interaction, $F(5,134)=$ $3.74, M S E=1,549.00, p<.01$ (see Figure 2). Although the precuing benefit for the short preparation interval of $100 \mathrm{~ms}$ was the same for all age groups, $F(5,134)=1.08, M S E=$ $317.75, p>.3$, the precuing benefit for the longer preparation interval of $2,000 \mathrm{~ms}$ varied as a function of age, $F(5$, $134)=3.93, M S E=527.11, p<.01$. Post hoc analysis indicated that for the longer preparation interval, the 55-yearold participants showed a larger precuing benefit than the 35-year-old and the 75-year-old participants, $p<.05$. In sum, the important finding is that, both with short and long preparation intervals, finger-precuing benefits generated by the hand-cued condition were not negatively affected by increasing age.

Most strikingly, the two-way interaction between age and stimulus-response position was significant, $F(15,402)=$ 7.23, $M S E=2,509.00, p<.001$. This interaction is graphically depicted in Figure 3 and indicates that the youngest age group of 25 years showed similar RTs in all four stimulus-response positions, but the age groups of 35 years and older showed increasingly pronounced inverted- $U$ or bowed-type RT functions. This new finding demonstrates that advancing age slows RT more to the inner than to the outer stimulus-response positions. Later, we discuss possible implications of this age-induced bowed stimulusresponse position effect.
Stimulus-response position also interacted with preparation condition, $F(3,402)=20.06, M S E=976.80, p<.001$, reflecting a steeper inverted- $U$ function for the uncued condition than for the hand-cued condition (see Figure 4). Probably, this effect is due to the precue transforming or converting the original four-element stimulus-response set into a new and smaller, left or right, two-element set that contains only outer (no inner) elements. In other words, the cue effectively removes the existence of inner elements by breaking or parsing the four-element set into a left or right two-element subset and thus takes away the need to discriminate between stimulus-response positions 2 and 3. This reduced need to discriminate between stimulus-response positions 2 and 3 may result in a more shallow function.

Errors. The overall error rate of $1.8 \%$ was low. Participants made more errors in the uncued than in the hand-cued condition ( 2.3 and $1.2 \%$, respectively), $F(1,134)=35.08$, $M S E=0.19, p<.001$. Percentage errors varied as a function of stimulus-response position in inverted- $U$ fashion $(1.3,2.1,2.3$, and $1.3 \%$ for left-to-right positions, respectively), $F(3,402)=7.66, M S E=0.19, p<.001$. With increasing age, participants tended to make more errors, $F(5,134)=2.01, M S E=0.40, p=.081,(1.3,1.4$, $1.6,1.9,1.6$, and $2.9 \%$ for ages $25,35,45,55,65$, and 75 years, respectively). Also, more errors tended to occur in the $100 \mathrm{~ms}$ than in the $2,000 \mathrm{~ms}$ preparation interval $(2.0$ and $1.6 \%$, respectively), $F(1,134)=3.73, M S E=0.18, p=$ .056 .

The two-way interaction between age and stimulusresponse position, $F(15,402)=1.80, M S E=0.19, p<.05$, indicated a steep inverted-U function for the 75-year-old participants $(1.4,3.1,4.7$, and $2.2 \%$ errors for left-to-right positions); all other age groups produced relatively flat functions with, on average, less than $2.0 \%$ errors. All other interactions were nonsignificant.
A: $100 \mathrm{~ms}$

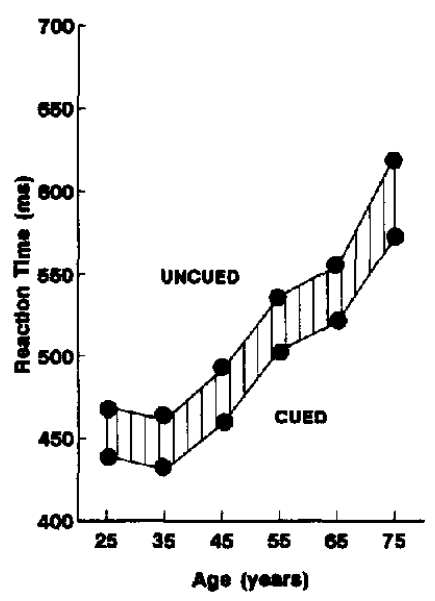

B: $2000 \mathrm{~ms}$

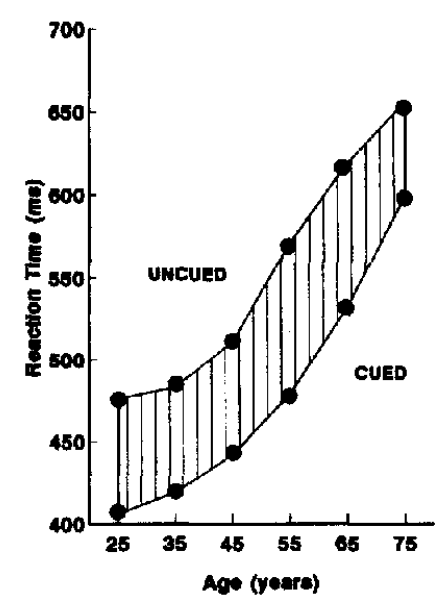

Figure 2. Mean reaction time in Experiment 1 as a function of age and preparation condition for (a) the short preparation interval of $100 \mathrm{~ms}$ and (b) the long preparation interval of $2,000 \mathrm{~ms}$. The shaded area denotes the precuing benefit. 


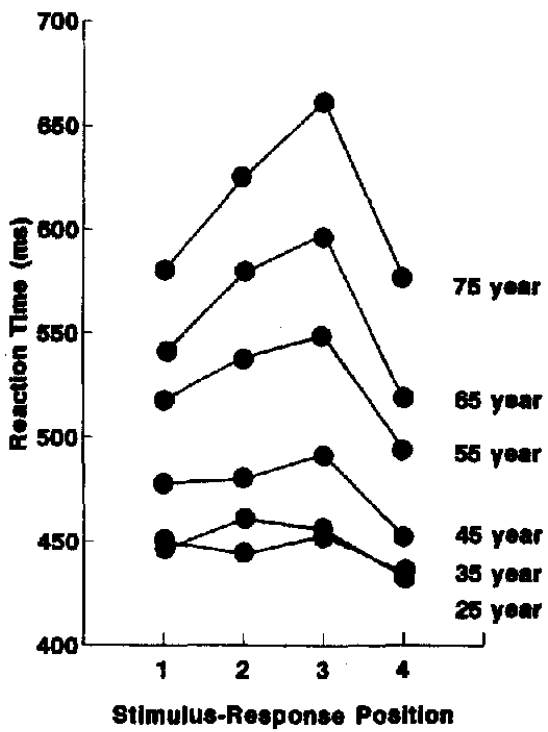

Figure 3. Mean reaction time in Experiment 1 as a function of age and stimulus-response position.

\section{Discussion}

Experiment 1 yielded two important results: (a) Fingerprecuing benefits produced by the hand-cued condition were not negatively affected by advancing age and (b) advancing age affected RT more to inner than to outer stimulusresponse positions. These two findings are discussed in turn.

Age-related precuing effects. The precuing effects established in Experiment 1 were at least as large in older as in younger adults. This outcome is not consistent with Hartley's (1993) hypothesis that age-related differences should be substantial when performance depends on attentional

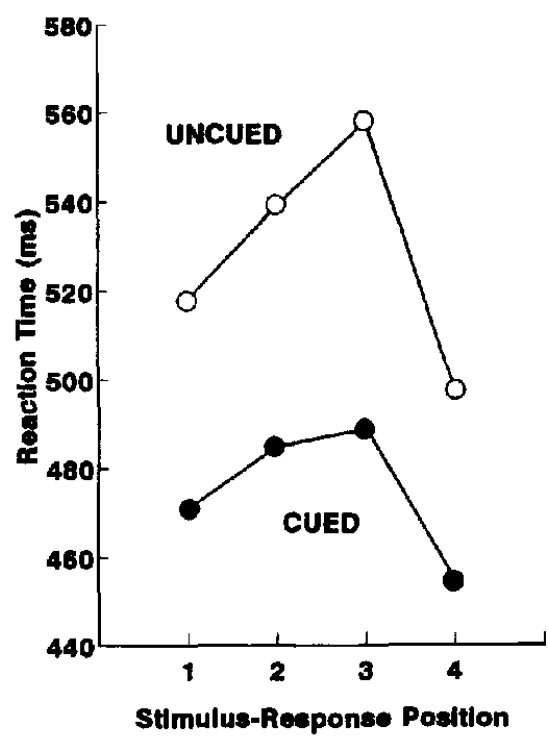

Figure 4. Mean reaction time in Experiment 1 as a function of preparation condition and stimulus-response position. selection-for-action. For the moment, we postpone discussing this unexpected finding until further experimentation in Experiment 2 examines its reliability and generality.

The age-related bowed stimulus-response position effect. A surprising discovery was that advancing age affected RT differentially as a function of the four stimulus-response positions. Specifically, 25-year-olds showed similar RTs in all four stimulus-response positions; older age groups, on the other hand, showed increasingly longer RTs to the inner than to the outer positions (see Figure 3) ${ }^{6}$ In other words, advancing age seems to transform an initially flat serial position curve into an increasingly bowed stimulusresponse position curve.

How can we explain this age-related bowed stimulusresponse position phenomenon? A promising possibility focuses on greater confusability for inner than for outer items. According to this idea, inner items are more confusable than outer items because inner items have two neighbors, whereas outer (or end) items have only one. The reason for the larger stimulus-response position effect in older participants could be that increments in neural noise and weaking of inhibition associated with advancing age might affect discriminability of inner items more than that of outer items (see also Discussion section of Experiment 2).

\section{Experiment 2}

The results of Experiment 1 indicate that advancing age does not negatively affect performance in the fingerprecuing task. However, Experiment 1 examined only one precue condition and two preparation intervals. Before accepting the generality of the findings of Experiment 1, it seemed prudent to determine whether the same effects would be obtained under different experimental conditions. Indeed, in order to provide a more complete picture of age-related finger-precuing effects, it seemed necessary to include the more difficult finger-cued and neither-cued conditions and also to provide a closer examination of the time course of precuing effects. Therefore, in Experiment 2, a group of younger and older research participants were asked to perform the finger-precuing task that included not only the uncued and hand-cued conditions of Experiment 1 but also the more difficult finger-cued and neither-cued conditions. In addition, three intermediate preparation intervals were added so that there were five preparation intervals: $100,500,1,000,1,500$, and $2,000 \mathrm{~ms}$.

\section{Method}

Participants. Twenty older adults and 20 younger adults participated as volunteers in this experiment. The older adults (10 men, 10 women) were recruited from the same population as in

\footnotetext{
${ }^{6}$ The data underlying Figure 3 are collapsed over preparation condition (and preparation interval). To simplify interpretation, however, the age-related bowed stimulus-response position effect is, for the present discussion, defined as referring to the uncued, that is, four-choice, condition. Notwithstanding the observed contamination, Figure 3 represents an adequate reflection of this definition.
} 
Experiment 1; they had an average age of 71.3 years (range, 70-73). Younger adults (10 men, 10 women) were students recruited from graduate courses at Maastricht University; they had an average age of 24.0 years (range, 20-27). All participants were right-handed by self-report, had normal or corrected-to-normal vision, and were in excellent health. The two age groups were not reliably different in terms of $1 Q, t(38)=0.64, p>.5(M s=123.4$ and 121.6 for younger and older participants, respectively).

Apparatus and stimuli. The apparatus and stimuli were the same as in Experiment 1, except that two additional cue signals were included, namely, the finger-cued and neither-cued signals. In the finger-cued condition, the cue signal occupied the two inner or two outer positions. In the neither-cued condition, the cue signal occupied the first and third or the second and fourth position.

Procedure. Five preparation intervals $(100,500,1,000,1,500$, and $2,000 \mathrm{~ms}$ ) and four precue conditions were used: hand-cued, finger-cued, neither-cued, and the control, uncued condition. Bach participant received a block of 80 trials for each preparation interval. A rest period of $3 \mathrm{~min}$ was provided between blocks. Within a block of 80 trials, there were 20 trials for each cue condition (and 5 trials for each of the four stimulus-response positions). The order of these cuing conditions within a block of 80 trials was random. Twenty practice trials preceded each block of $\mathbf{8 0}$ test trials. Otherwise, the procedure was identical to Experiment 1.

Analysis. RTs of less than $150 \mathrm{~ms}$ or in excess of $1.5 \mathrm{~s}$ were considered outliers and were excluded from data analysis; less than $0.4 \%$ of the RTs were removed using this criterion. A split-plot ANOVA was performed on mean RTs and percentage errors, with age as the between-subjects variable and preparation condition (uncued, hand-cued, finger-cued, and neither-cued), preparation interval $(100,500,1,000,1,500$, and $2,000 \mathrm{~ms})$, and stimulusresponse position $(1,2,3$, and 4$)$ as within-subject variables.

\section{Results}

Reaction time. There were significant main effects for age, $F(1,38)=123.61, M S E=292,632.00, p<.001$; preparation condition, $F(3,114)=56.75, M S E=8,679.00$, $p<.001$; preparation interval, $F(4,152)=4.81, M S E=$ $23,773.00, p<.01$; and stimulus-response position, $F(3$, $114)=36.70, M S E=14,896.00, p<.001$. These main effects indicated longer RTs for older than for younger participants (610 and $398 \mathrm{~ms}$, respectively), a differential pattern of RT as a function of precue condition $(471,504$, 511 , and $531 \mathrm{~ms}$ for the hand-cued, finger-cued, neithercued, and uncued conditions, respectively), a U-shaped pattern of RT as a function of preparation interval $(522,495$, 494,496 , and $514 \mathrm{~ms}$ for preparation intervals 100,500 , $1,000,1,500$, and $2,000 \mathrm{~ms}$, respectively), and an inverted- $U$ pattem of RT as a function of stimulus-response position (493, 534,516 , and $477 \mathrm{~ms}$ for left-to-right positions, respectively). These main effects were qualified by interactions.

First, and most important, there was a significant Age $\times$ Preparation Condition interaction, $F(3,114)=9.25, M S E=$ $8,679.00, p<.001$, indicating that precue effectiveness varied as a function of age (see Figure 5). The younger participants showed the usual pattern of differential precuing benefits with shortest RTs for the hand-cued condition ( 374 $\mathrm{ms}$ ), longest RTs for the neither-cued condition (399 ms), and intermediate RTs for the finger-cued condition $(387 \mathrm{~ms})$. All these RTs were significantly shorter $(p<.001)$ than the

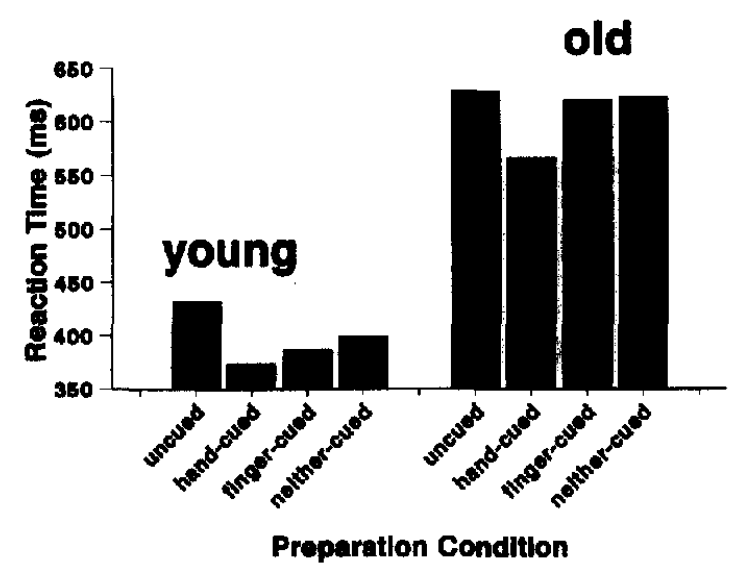

Figure 5. Mean reaction time in Experiment 2 as a function of preparation condition for younger and older participants.

RTs in the uncued condition ( $432 \mathrm{~ms}$ ), indicating significant (although different) amounts of RT facilitation for the hand-cued, finger-cued, and neither-cued conditions. The older participants, on the other hand, showed a different pattern of precuing benefits; only RTs in the hand-cued condition $(567 \mathrm{~ms})$ were significantly shorter than those in the uncued condition $(629 \mathrm{~ms})$, with RTs in the finger-cued, neither-cued, and uncued conditions not being significantly different $(620,623$, and $629 \mathrm{~ms}$, respectively; $p>.4)$.

A separate ANOVA comparing the RT precuing benefits for younger and older adults as a function of precuing condition (i.e., hand-cued, finger-cued, and neither-cued) yielded a significant interaction between age and precuing condition, $F(2,76)=12.90, M S E=355.40, p<.001$, indicating age-equivalence for hand-cued precuing benefits (58 and $62 \mathrm{~ms}$, respectively) but significant age-deficiencies for finger-cued ( 45 and $9 \mathrm{~ms}$, respectively) and neither-cued ( 33 and $6 \mathrm{~ms}$, respectively) benefits.

The significant three-way Age $\times$ Preparation Condition $X$ Preparation Interval interaction, $F(12,432)=2.00, M S E=$ $3,170.00, p<.05$, qualified this picture somewhat by indicating that older participants were indeed able to reduce RT in the finger-cued and neither-cued conditions but only with the longest preparation intervals of 1,500 and $2,000 \mathrm{~ms}$ (see Figure 6b) and only to a modest extent. This result is in sharp contrast with the younger participants, who generated relatively quickly substantial finger-cued and neither-cued precuing benefits, that is, within the first $1,000 \mathrm{~ms}$ of preparation time (see Figure 6a). Precuing benefits that were due to the hand-cued condition, on the other hand, accrued extremely quickly (significant benefits within the first 100 $\mathrm{ms}$ of preparation time) and reached optimum values after $500 \mathrm{~ms}$, both for the younger and older participants.

The significant Age $\times$ Preparation Interval interaction, $F(4,144)=2.53, M S E=23,937.00, p<.05$, indicated that the upward bend in the $U$-shaped reaction function relating RT to preparation interval occurred sooner for older adults (i.e., after $500 \mathrm{~ms}$ ) than for younger adults (i.e., after 1,000 $\mathrm{ms})$. In other words, slowing of RT due to lengthening of preparation interval started earlier (i.e., with shorter prepara- 


\section{A: Young}

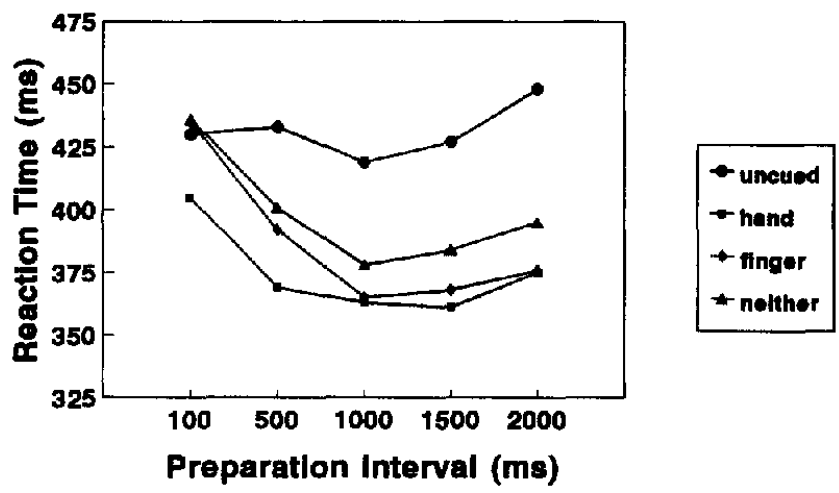

B: OLD

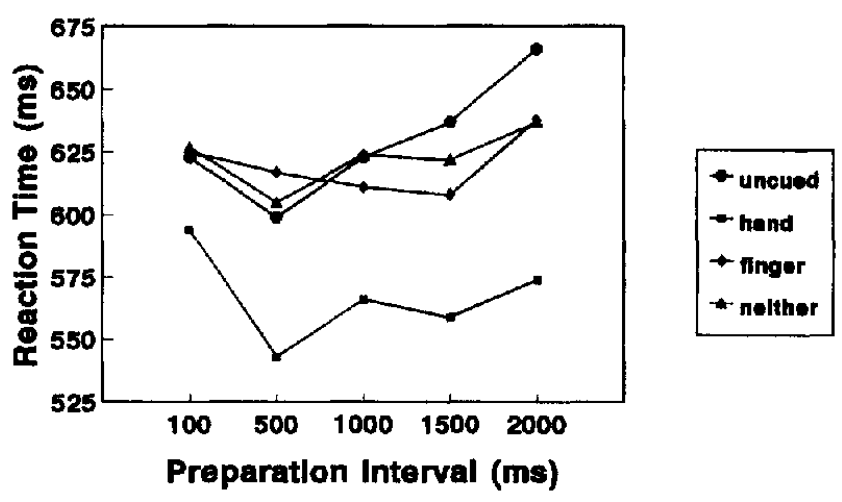

Figure 6. Mean reaction time in Experiment 2 as a function of preparation condition and preparation interval for younger and older participants.

tion intervals) for older than for younger adults ( $M$ s for older participants $=617,591,606,606$, and $629 \mathrm{~ms}$ for preparation intervals $100,500,1,000,1,500$, and 2,000, respectively; $M$ s for younger participants $=426,399,381,385$, and $399 \mathrm{~ms}$ for preparation intervals $100,500,1,000,1,500$, and 2,000, respectively). Moreover, the degree or amount of RT slowing due to preparation interval lengthening (i.e., the height of the upward bend) was twice as large for the older participants $(38 \mathrm{~ms})$ as for the younger participants $(18 \mathrm{~ms})$.

An important result was that, as in Experiment 1, age interacted with stimulus-response position, $F(3,108)=$ 18.55, $M S E=15,297.00, p<.001$. This interaction indicated that although younger participants produced a relatively flat RT curve as a function of the four stimulusresponse positions, older participants showed a distinct inverted-U or bowed function, with inner elements yielding substantially longer RTs than outer elements (see Figure 7a).

Stimulus-response position also interacted with preparation condition, $F(9,342)=4.33, M S E=4,153.00, p<$
.001 , reflecting a less steep inverted- $U$ function for the hand-cued condition than for the finger-cued, neither-cued, and uncued conditions, which all showed steep inverted-U functions (see Figure 8).

Errors. Overall error rate was 3.1\%. Older participants made more errors than younger participants (4.2 and $2.1 \%$, respectively), $F(1,36)=13.32, M S E=0.65, p<.001$. Participants made more errors in the finger-cued $(3.8 \%)$ and neither-cued (3.5\%) conditions than in both the hand-cued $(2.4 \%)$ and uncued $(2.9 \%)$ conditions, $F(3,108)=4.22$, $M S E=0.19, p<.01$. Percentage errors varied as a function of stimulus-response position in an inverted- $U$ fashion (2.0, $4.4,4.2$, and $1.9 \%$ for left-to-right positions, respectively), $F(3,108)=18.72, M S E=0.20, p<.001$. As in the RT analysis, these main effects were qualified by interactions.

First, the significant two-way interaction between age and preparation condition, $F(3,108)=4.40, M S E=0.19, p<$ .01 , indicated that the older participants made more errors in the cued conditions than in the uncued condition (3.8, 5.4, 4.5 , and $3.1 \%$ for the hand-cued, finger-cued, neither-cued, and uncued conditions, respectively), whereas the younger participants made fewer errors in the cued conditions than in the uncued condition $(1,2.1,2.6$, and $2.7 \%$ for the handcued, finger-cued, neither-cued, and uncued conditions, respectively). Second, age interacted with preparation interval, $F(4,144)=3.17, M S E=0.22, p<.02$, indicating that the younger participants made less errors with longer preparation intervals $(3.3,2.6,1.6,1.5$, and $1.5 \%$ for preparation intervals of $100,500,1,000,1,500$, and 2,000 ms, respectively), whereas the older participants made the most errors in the longest preparation interval of $2,000 \mathrm{~ms}$ $(3.9,3.4,4.5,3.9$, and $5.2 \%$ of errors for preparation intervals of $100,500,1,000,1,500$, and $2,000 \mathrm{~ms}$, respectively). Third, the two-way interaction between age and stimulus-response position, $F(3,108)=7.47, M S E=0.20$, $p<.001$, indicated a much steeper inverted- $U$ function for the older participants $(2.3,6.4,5.8$, and $2.2 \%$ errors for left-to-right positions) than for the younger participants (1.8, $2.5,2.6$, and $1.6 \%$ errors for left-to-right positions; see Figure 7b).

\section{Discussion}

Age-related precuing effects. The results of Experiment 2 showed that older participants were only marginally able to reduce RT in the finger-cued and neither-cued conditions. Also these conditions showed the largest error rates. These outcomes indicate that older participants have great difficulty preparing two fingers on different hands. In contrast, and as in Experiment 1, the RT benefit for the hand-cued condition (relative to the uncued condition) was not signifcantly different for younger and older participants, suggesting age equivalence in performance. However, older participants did make more errors in this condition than did younger participants, suggesting that performance in the hand-cued condition is not completely preserved with advancing age. In summary, the results of Experiment 2 demon- 
A: REACTION TIME

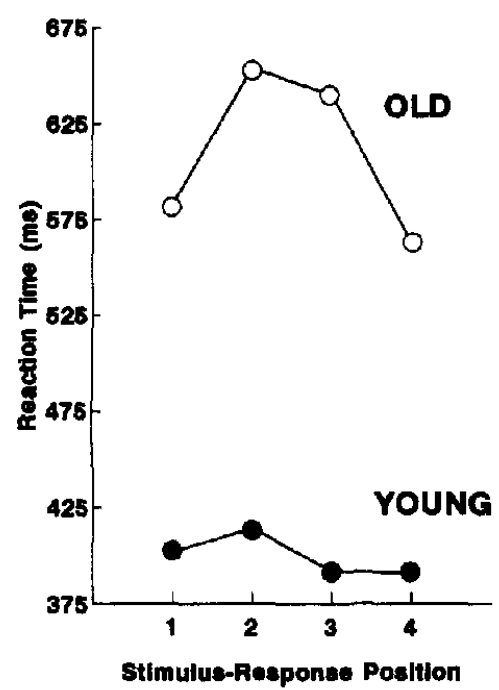

\section{B: ERRORS}

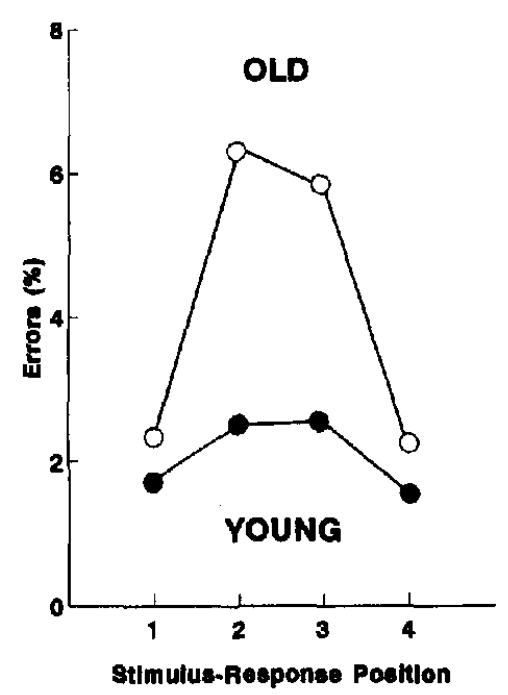

Figure 7. (a) Mean reaction time and (b) percentage of errors in Experiment 2 as a function of stimulus-response position for younger and older participants.

strate that older participants encounter great difficulty preparing two fingers on different hands but encounter less difficulty preparing two fingers on one hand. This disparate set of findings does not provide strong support for Hartley's hypothesis that age-related differences are large when performance depends on selection-for-action.

It is tempting to speculate about the reason why advancing age selectively impairs RT performance in the fingercued and neither-cued conditions but not (or to a lesser

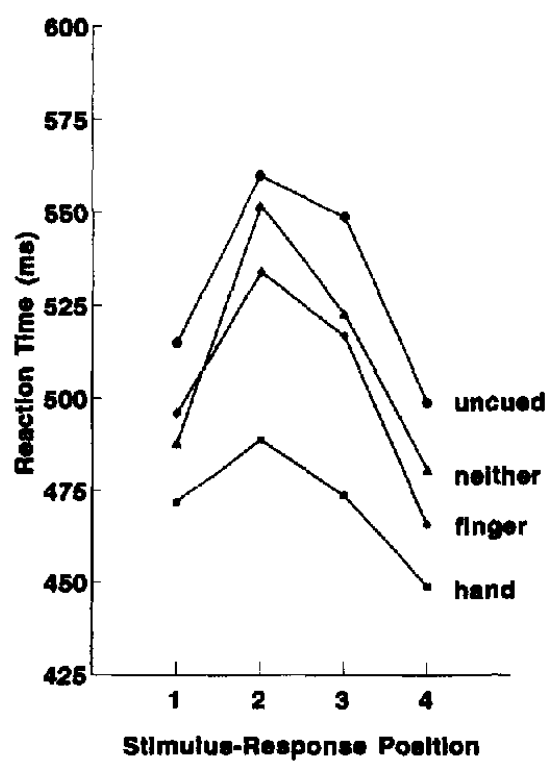

Figure 8. Mean reaction time in Experiment 2 as a function of preparation condition and stimulus-response position. extent) in the hand-cued condition. Attempts to explain this phenomenon should take into consideration that the handcued condition not only shows this advantage but also shows the advantage that its precuing benefits accrue extremely quickly. That is, precuing benefits typically accrue much more quickly (i.e., need shorter preparation intervals to materialize) in the hand-cued condition than in the fingercued and neither-cued conditions. To be specific, in Experiment 2, significant precuing benefits were manifest in the shortest preparation interval of $100 \mathrm{~ms}$ for the hand-cued condition but not for the finger-cued or neither-cued conditions (see Figure 6; see also Reeve \& Proctor, 1984). In fact, preparation intervals as short as $60 \mathrm{~ms}$ have been shown to be effective in generating substantial $(30 \mathrm{~ms})$ hand-cued benefits (Adam, 1994).

Thus, precuing benefits in the hand-cued condition differ from those in the finger-cued and neither-cued conditions in at least two important respects: (a) They accrue extremely quickly (i.e., significant gains in the first $100 \mathrm{~ms}$ ), and (b) they are marginally affected by advancing age. We argue that these two phenomena may be interpreted as suggesting a qualitative difference between hand-cued and finger-cued/ neither-cued benefits, thereby allowing the possibility of qualitatively different underlying mechanisms.

It has been proposed that there are at least two distinct mechanisms by which spatial precues can facilitate (perceptual) performance, namely, resource allocation and location uncertainty reduction (e.g., Luck, Hillyard, Mouloua, \& Hawkins, 1996; Palmer, Ames, \& Lindsey, 1993; Shaw, 1984; Sperling, 1984; Sperling \& Dosher, 1986). The resource allocation model assumes that precuing effects result from the focused allocation of limited processing resources to the target location. The uncertainty reduction 
model is based on statistical decision theory and argues that performance is a direct function of the amount of uncertainty (or noise) regarding the target location.

According to the uncertainty reduction view, spatial precues reduce uncertainty (or noise) by limiting the number of sources of information that actually contribute to the decision. Specifically, if a target stimulus can occur at several locations, and the cue indicates the likely location of that target, observers can improve performance by inspecting only information from the cued location. By using this strategy, observers can exclude noise from uncued locations from the decision process, leading to improved performance. This uncertainty reduction model of spatial precuing differs from the resource allocation model in that the precuing benefit can be explained without reference to limited processing resources.

It should be noted that even though the uncertainty reduction model has been developed in the context of perceptual-precuing tasks, it also applies to the fingerprecuing task because it does not imply any particular locus of selection (Shiu \& Pashler, 1994). That is, cuing the most likely stimulus-response positions allows noise to be excluded, attenuated, or weighted less before stimulus identification but also after stimulus identification, that is, during the process of response selection.

Luck et al. (1996) contended that either or both of these two mechanisms (i.e., resource allocation and uncertainty reduction) might be used in a given situation, depending on the nature of the stimuli and task. They further argued and demonstrated that uncertainty reduction can operate much more quickly than resource allocation. That is, uncertainty reduction can operate with little or no delay between the cue signal and the target, but resource allocation requires longer cue-target delays. As we have seen, precuing benefits in the hand-cued condition also accrue extremely quickly, but finger-cued and neither-cued benefits need considerably longer periods of preparation time to develop.

Applying the resource allocation/uncertainty reduction distinction to performance in the finger-precuing task, it could, perhaps, be speculated that both mechanisms underly in different degrees hand-cued benefits and finger-cued/ neither-cued benefits, with hand-cued benefits generated more by the mechanism of uncertainty reduction than by resource allocation, and finger-cued/neither-cued benefits stemming more from resource allocation than from uncertainty reduction. The rationale for this idea is the observation that the spatial cue in the hand-cued condition directly and unambiguously halves uncertainty by partitioning or dividing the perceptual-motor work space in distinct left and right parts. This advantage does not hold for the finger-cued and neither-cued conditions whose spatial cues prepare stimulusresponse elements situated on both the left and right side of the perceptual-motor work space.

The finding that the RT advantage of the hand-cued condition relative to the finger-cued and neither-cued conditions was significantly larger for the inner than for the outer stimulus-response elements (see Figure 8) might further illustrate why and how the left-right distinction is particularly effective in reducing uncertainty and thus RT. First, note that all three precuing conditions create two-element subgroups. However, the pattern of differential precuing benefits suggests that some subgroups are easier to create than others. Second, note that in the uncued condition, RT is slowest for the inner positions, presumably because these inner positions have two direct neighbors whereas outer positions only have one direct neighbor. According to this line of reasoning, cues will be particularly effective if they succeed in removing or eliminating these inner elements (elements 2 and 3 ) as potential stimulus-response alternatives from the decision process. Now, the hand-cued condition might be particularly effective in doing this because it bisects the perceptual-motor space in two distinct parts, thereby effectively eliminating two irrelevant stimulusresponse alternatives, including one of the two inner elements. This is not the case for the finger-cued and neithercued conditions because they create two-element subsets that always either explicitly or implicitly include or virtually encompass the inner elements (stimulus-response positions 2 and 3). Notice that in this view even an empty stimulusresponse location may introduce substantial noise. In other words, the finger-cued and neither-cued two-element stimulus-response sets are not finely tuned and consequently might require controlled processing (i.e., resource allocation) to achieve this state.

According to the resource allocation/uncertainty reduction approach, the substantial aging effect for the finger-cued and neither-cued conditions and the relative absence of such an effect for the hand-cued condition might be attributed to the notion that advancing age is accompanied by a reduction in attentional resources (e.g., Allen, Groth, Weber, \& Madden, 1993; Salthouse, 1988), although automatic processes are left intact (e.g., Hasher \& Zacks, 1979; Hoyer \& Plude, 1980).

Of course, extensive investigations are needed to examine the validity of these speculations, but at least two alternative interpretations of the hand-cued advantage can be dismissed. One alternative interpretation focuses on the notion that cerebral control of hand and finger movements is almost completely localized in the contralateral frontal lobe (e.g., Gazzaniga, 1970). According to this view, the advantage of the hand-cued condition over the finger-cued and neithercued conditions originates in the fact that the hand-cued condition prepares two fingers controlled by one hemisphere, whereas the finger-cued and neither-cued conditions prepare two fingers controlled by two hemispheres. This hypothesis can be rejected because Reeve and Proctor (1984) showed that, with an overlapped placement of hands (i.e., with fingers of both hands alternating on response keys in the following order: right index, left middle, right middle, left index), the usual advantage for the hand-cued condition (two fingers on one hand) switches to an advantage for the neither-cued condition (different fingers on different hands). In other words, the hand-cued advantage is really an advantage for the two left-most and two right-most stimulusresponse locations, not for the left or right hand per se (Reeve \& Proctor, 1984, Experiment 3).

This observation suggests a second alternative interpretation of the advantage of the hand-cued condition over the 
finger-cued and neither-cued conditions. Miller (1982) observed that preparation for two stimulus positions might be more efficient the closer together they are, possibly because of an advantage in sharing attention across nearby positions. According to this spatial-proximity hypothesis, preparation is most effective in the hand-cued condition because the two primed positions are close together (Miller, 1982). However, Miller (1982) rejected the spatial-proximity hypothesis because the observed effects did not support the explanation (see also Adam, 1992; Reeve \& Proctor, 1984). Miller (1982) argued that because the cue preparing the two index fingers is only half as far apart as the cue preparing the two middle fingers, preparation should be greater for the index fingers than for the middle fingers. However, preparation benefits were virtually identical for preparing two middle or two index fingers. The results of our Experiment 2 showed the same outcome (i.e., preparation benefits of 26 and $29 \mathrm{~ms}$ for the middle fingers and index fingers in the finger-cued condition, respectively; see Figure 8).

Finally, it could be argued that, at least in principle, preparation intervals longer than $2 \mathrm{~s}$ would allow older participants to show the same precuing benefits as those of younger participants. This possibility is not particularly plausible, however, because in Experiment 2 older participants more than younger participants were negatively affected by increasing the duration of the preparation interval. That is, slowing of RT due to lengthening of the preparation interval started sooner and was more pronounced for older than for younger participants. Also, in the longest preparation interval of $2 \mathrm{~s}$, older participants made the most errors and younger participants made the fewest errors. Furthermore, although younger participants were less error-prone in the cued conditions than in the uncued condition, older participants were more error-prone in the cued-conditions than in the uncued condition. At any rate, besides these counterindications, the above-mentioned possibility in no way compromises the present conclusion that older participants encounter great difficulty preparing two fingers on different hands but less difficulty preparing two fingers on one hand.

The age-related bowed stimulus-response position effect. As in the previous experiment, results indicated that older age affected inner stimulus-response positions more than outer stimulus-response positions. That is, responses were much slower and more error-prone for inner than for outer positions. In the discussion of Experiment 1, we argued that the concept of greater confusability for inner than for outer items might provide a useful theoretical framework. According to this approach, inner items are more confusable than outer items because inner items have two neighbors, whereas outer (or end) items have only one.

Two age-related phenomena may differentially affect confusability of inner and outer items. Increments in neural noise (e.g., Crossman \& Szafran, 1956; Welford, 1980) and weakening of inhibition (e.g., Hasher \& Zacks, 1979; Kane, Hasher, Stoltzfus, Zacks, \& Connelly, 1994; McDowd \& Filion, 1992) associated with advancing age might affect discriminability of inner items more than that of outer items. Within this framework, a basic question for future research is whether confusability relates to stimulus-based processing, response-based processing, or some combination of the two.

Why were the specific shapes of the inverted-U type functions relating RT to stimulus-response position different in the two experiments? Specifically, why in Experiment 1 did the third stimulus-response position yield slower RTs than the second stimulus-response position (see Figure 3), whereas this pattern reversed in Experiment 2 (see Figure 7)? This discrepant set of findings might be related to procedural differences. In Experiment $1,50 \%$ of the trials consisted of the uncued condition and 50\% consisted of the hand-cued condition. In Experiment 2, there were four precue conditions (i.e., uncued, hand-cued, finger-cued, and neither-cued), all randomly intermixed and each appearing in $25 \%$ of the trials. Perhaps the large proportion of uncued trials (i.e., the four-choice control condition) in Experiment 1 induced a serial, left-to-right processing strategy. In Experiment 2, on the other hand, the uncued condition appeared only in $20 \%$ of the trials, whereas in addition the remaining trials contained three different types of precue (i.e., hand-cued, finger-cued, and neither-cued), thereby possibly precluding a left-to-right processing strategy.

Generalized slowing. Theorists who postulate a generalized slowing of processing with advancing age (e.g., Cerella, 1985; Myerson, Hale, Wagstaff, Poon, \& Smith, 1990) would argue that RT benefits due to precues should be expressed and evaluated in relative units, not in absolute units. That is, according to general slowing models, a benefit of, for example, $50 \mathrm{~ms}$ would be relatively larger for younger (faster baseline) participants than for older (slower baseline) adults. Hence, a pattern of equivalent precuing benefits in absolute units for older and younger participants would, when expressed in relative terms, actually suggest an age-related deficit. This argument is especially relevant for the hand-cued condition, which, in both Experiments 1 and 2, yielded similar, but not identical, (absolute) precuing benefits for older and younger participants. Would the conclusion that hand-cued benefits are relatively unaffected by advancing age still hold when expressed in relative units?

To answer this question, we calculated hand-cued precuing benefits in terms of relative or proportional units (i.e., as a proportion of the baseline RT value provided by the uncued condition). For Experiment 1, the proportional precuing effect for the three youngest age groups was identical to the proportional precuing effect for the three oldest age groups, namely, 0.10 (averaged over preparation interval). For Experiment 2, the proportional precuing effect of the older participants was slightly less $(0.10)$ than that of the younger participants $(0.13)$. Therefore, the conclusion seems justified that hand-based precuing benefits are relatively well-preserved with advancing age in both absolute and relative terms.

As noted, several authors have suggested that age-related slowing equally affects all cognitive processes within some broadly defined domain (e.g., Cerella, 1985; Meyerson et al., 1990). That is, advancing age is seen as being associated with a general, quantitative change in information processing speed as opposed to a change in specific processes or 
qualitative change. It is relevant to note, however, that general slowing models explicitly allow for domain-specific changes. For example, Cerella's multilayered slowing model assumes that the age-related slowing of cognitive processes is more extensive than the age-related slowing of perceptual processes. The present results seem to indicate that agerelated slowing of finger-precuing effects (i.e., finger-cued and neither-cued) is more extensive than age-related slowing of perceptual precuing effects.

\section{Conclusion}

Considerable research over the last decade has indicated that perceptual precuing performance is relatively unaffected by older age. In contrast, the present study showed a substantial age-related deficit in preparing two fingers on different hands. However, the ability to prepare two fingers on one hand was relatively well preserved. At present, this mixed pattern of results does not support Hartley's (1993) hypothesis that age-related differences are large when performance depends on selection-for-action. More conclusive interpretation awaits solution of the mysterious hand advantage or, more appropriate, the side advantage. A promising direction for possible interpretation would focus on the idea that two distinct mechanisms might mediate precuing performance: resource allocation and uncertainty reduction.

An important additional outcome emerged, namely, the finding of age-related differences in RT as a function of stimulus-response position: the bowed stimulus-response position effect. Although presently misunderstood, this phenomenon seems to be of sufficient theoretical and practical significance to warrant continued investigation.

\section{References}

Adam, J. J. (1992). The spatial proximity hypothesis of the hand advantage in spatial precuing tasks. Human Movement Science, $11,641-652$.

Adam, J. J. (1994). Manipulating the spatial arrangement of stimuli in a precuing task. Acta Psychologica, 85, 183-202.

Adam, J. J., \& Van Veggel, L. M. A. (1992). Manipulating procedural variables in a spatial precuing task. Acta Psychologica, 81, 97-114.

Allen, P. A., Groth, K. E., Weber, T. A., \& Madden, D. J. (1993). Influence of response selection and noise similarity on age differences in the redundancy gain. Joumal of Gerontology: Psychological Sciences, 48, P189-P198.

Allport, D. A. (1987). Selection for action: Some behavioral and neurophysiological considerations of attention and action. In H. Heuer \& A. F. Sanders (Eds.), Perspectives on perception and action (pp. 395-419). Hillsdale, NJ: Erlbaum.

Bashinski, H. S., \& Bacharach, V. R. (1980). Enhancement of perceptual sensitivity as the result of selectively attending to spatial locations. Perception \& Psychophysics, 28, 241-248.

Brown, T. L. (1996). Attentional selection and word processing in Stroop and word search tasks: The role of selection for action. American Journal of Psychology, 109, 265-286.

Carr, T. H. (1992). Automaticity and cognitive anatomy: Is word recognition "automatic"? American Journal of Psychology, 105, 201-237.

Cerella, J. (1985). Information processing rates in the elderly. Psychological Bulletin, 98, 67-83.
Cheal, M., \& Lyon, D. R. (1991). Benefits from attention depend on the target type in location-precued discrimination. Acta Psychologica, 81, 243-267.

Craik, F. I. M., Morris, L. W., Morris, R. G., \& Loewen, E. R. (1990). Relations between source amnesia and frontal lobe functioning in older adults. Psychology and Aging, 5, 148-151.

Crossman, E. R. F. W., \& Szafran, J. (1956). Changes with age in the speed of information intake and discrimination. Experientia Supplementum, 4, 128-135.

Davis, A., \& Annett, M. (1994). Handedness as a function of twinning, age and sex. Cortex, 30, 105-111.

de Jong, R., Wierda, M., Mulder, G., \& Mulder, L. J. M. (1988). Use of partial stimulus information in response processing. Journal of Experimental Psychology: Human Perception and Performance, 14, 682-692.

Elias, M. F., Elias, J. W., \& Elias, P. K. (1990). Biological and health influences on behaviour. In J. E. Birren \& K. W. Schaie (Eds.), Handbook of the psychology of aging (3rd ed., pp. 79-102). San Diego, CA: Academic Press.

Eriksen, C. W. (1990). Attentional search of the visual field. In D. Brogan (Ed.), Visual search (pp. 3-19). London: Taylor \& Francis.

Eriksen, C. W., \& Rohrbaugh, J. W. (1970). Some factors determining efficiency of selective attention. American Journal of Psychology, 83, 330-342.

Folk, C. L., \& Hoyer, W. J. (1992). Aging and shifts of visual spatial attention. Psychology and Aging, 7, 453-465.

Gazzaniga, M. (1970). The bisected brain. New York: AppletonCentury-Crofts.

Goldberg, M. E., \& Segraves, M. A. (1987). Visuospatial and motor attention in the monkey. Neuropsychologia, 25, 107-118.

Greenwood, P., Parasuraman, R., \& Haxby, J. (1993). Changes in visuospatial attention over the adult lifespan. Neuropsychologia, $3 I, 471-485$.

Hartley, A. A. (1993). Evidence for the selective preservation of spatial selective attention in old age. Psychology and Aging, 8, 371-379.

Hartley, A. A., Kieley, J. M., \& McKenzie, C. R. M. (1992). Allocation of visual attention in younger and older adults. Perception \& Psychophysics, 52, 175-185.

Hartley, A. A., Kieley, J. M., \& Slabach, E. H. (1990). Age differences and similarities in the effects of cues and prompts. Journal of Experimental Psychology: Human Perception and Performance, 16, 523-537.

Hartley, A. A., \& McKenzie, C. R. M. (1991). Attentional and perceptual contributions to the identification of extrafoveal stimuli: Adult age comparisons. Joumal of Gerontology: Psychological Sciences, 46, P202-P206.

Hasher, L., \& Zacks, R. T. (1979). Automatic and effortful processes in memory. Journal of Experimental Psychology: General, 108, 356-388.

Heilman, K. M., Watson, R. T., \& Valenstein, E. (1985). Neglect and related disorders. In K. M. Heilman \& E. Valenstein (Eds.), Clinical neuropsychology (2nd ed., pp. 243-294). New York: Oxford University Press.

Henderson, J. M. (1991). Stimulus discrimination following covert attentional orienting to an exogenous cue. Journal of Experimental Psychology: Human Perception and Performance, 17, 91106.

Hick, W. E. (1952). On the rate of gain of information. Quarterly Journal of Experimental Psychology, 4, 11-26.

Hoffman, J. E. (1975). Hierarchical stages in the processing of visual information. Perception \& Psychophysics, 18, 348-354. 
Houx, P. J., \& Jolles, J. (1993). Vulnerability factors for age-related cognitive decline. In R. L. Isaacson \& K. F. Jensen (Eds.), Toxins in air and water (pp. 25-41). New York: Plenum Press.

Hoyer, W. J., \& Familant, M. E. (1987). Adult age differences in the rate of processing expectancy information. Cognitive Development, 2, 59-70.

Hoyer, W. J., \& Plude, D. J. (1980). Attentional and perceptual processes in the study of cognitive aging. In L. W. Poon (Ed.), Aging in the 1980s: Psychological issues (pp. 227-238). Washington, DC: American Psychological Association.

Hyman, R. (1953). Stimulus information as a determinant of reaction time. Journal of Experimental Psychology, 45, 188196.

Jolles, J., Houx, P. H., van Boxtel, M. P. J., \& Ponds, R. W. H. M. (1995). The Maastricht aging study: Determinants of cognitive aging. Maastricht, The Netherlands: Neuropsych Publishers.

Kane, M. J., Hasher, L., Stoltzfus, E. R., Zacks, R. T., \& Connelly, S. L. (1994). Inhibitory attentional mechanisms and aging. Psychology and Aging, 9, 103-112.

Keppel, G. (1982). Design and analysis. Englewood Cliffs, NJ: Prentice Hall.

Leuthold, H., Sommer, W., \& Ulrich, R. (1996). Partial advance information and response preparation: Inferences from the lateralized readiness potential. Journal of Experimental Psychology: General, 125, 307-323.

Luck, S. J., Hillyard, S. A., Mouloua, M., \& Hawkins, H. L. (1996). Mechanisms of visual-spatial attention: Resource allocation or uncertainty reduction? Journal of Experimental Psychology: Human Perception and Performance, 22, 725-737.

Luteijn, F., \& van der Ploeg, F. A. E. (1983). Handleiding Groningen Intelligentietest (GIT) [Manual Groningen Intelligence Test]. Lisse, The Netherlands: Swets \& Zeitlinger.

Lyon, D. R. (1990). Large and rapid improvement in form discrimination accuracy following a location precue. Acta Psychologica, 73, 69-82.

Madden, D. J., \& Plude, D. J. (1993). Selective preservation of selective attention. In J. Cerella, J. Rybash, W. Hoyer, \& M. L. Commons (Eds.), Adult information processing: Limits on loss (pp. 273-300). San Diego, CA: Academic Press.

McDowd, J. M., \& Birren, J. E. (1990). Aging and attentional processes. In J. E. Birren \& K. W. Schaie (Eds.), Handbook of the psychology of aging (3rd ed., pp. 222-233). San Diego, CA: Academic Press.

McDowd, J. M., \& Filion, D. L. (1992). Aging, selective attention, and inhibitory processes: A psychophysiological approach. Psychology and Aging, 7, 65-71.

Metsemakers, J. F. M., Höppener, P., Knottnerus, J. A., Kocken, R. J. J., \& Limonard, C. B. G. (1992). Computerized health information in the Netherlands: A registration network of family practices. British Joumal of General Practice, 42, 102-106.

Miller, J. (1982). Discrete versus continuous models of human information processing: In search of partial output. Journal of Experimental Psychology: Human Perception and Performance, 8, 273-296.

Miller, J. (1985). A hand advantage in preparation of simple keypress responses: Reply to Reeve and Proctor (1984). Journal of Experimental Psychology: Human Perception and Performance, 11, 221-233.

Myerson, J., Hale, S., Wagstaff, D., Poon, L. W., \& Smith, G. A. (1990). The information-loss model: A mathematical theory of age-related cognitive slowing. Psychological Review, 97, 475487.

Nissen, M. J., \& Corkin, S. (1985). Effectiveness of attentional cueing in older and younger adults. Journal of Gerontology, 40, 185-191.
Palmer, J., Ames, C. T., \& Lindsey, D. T. (1993). Measuring the effect of attention on simple visual search. Joumal of Experimental Psychology: Human Perception and Performance, 19, 108130.

Pashler, H. (1991). Shifting visual attention and selecting motor responses: Distinct attentional mechanisms. Journal of Experimental Psychology: Human Perception and Performance, 17. 1023-1040.

Posner, M. I. (1980). Orienting of attention. Quarterly Journal of Experimental Psychology, 32, 3-25.

Posner, M. I., \& Petersen, S. E. (1990). The attention system of the human brain. Annual Review of Neuroscience, 13, 25-42.

Posner, M. I., Snyder, C. R. R., \& Davidson, B. J. (1980). Attention and the detection of signals. Journal of Experimental Psychology: General, 109, 160-174.

Proctor, R. W., \& Reeve, T. G. (1988). The acquisition of task-specific productions and modification of declarative representations in spatial-precuing tasks. Journal of Experimental Psychology: General, 117, 182-196.

Reeve, T. G., \& Proctor, R. W. (1984). On the advance preparation of discrete finger responses. Journal of Experimental Psychology: Human Perception and Performance, 10, 541-553.

Reeve, T. G., \& Proctor, R. W. (1985). Non-motoric translation processes in the preparation of discrete finger responses: $A$ rebuttal of Miller's (1985) analysis. Joumal of Experimental Psychology: Human Perception and Performance, 11, 234-240.

Reeve, T. G., \& Proctor, R. W. (1990). The salient-features coding principle for spatial- and symbolic-compatibility effects. In R. W. Proctor \& T. G. Reeve (Eds.), Stimulus-response compatibility (pp. 163-180). Amsterdam: North-Holland.

Requin, J., Brener, J., \& Ring, C. (1991). Preparation for action. In J. R. Jennings \& M. G. H. Coles (Eds.), Handbook of cognitive psychophysiology (pp. 357-448). Orichester, England: Wiley.

Requin, J., Riehle, A., \& Seal, J. (1993). Neural networks for movement preparation. In D. E. Meyer \& S. Kornblum (Eds.), Attention and performance (Vol. 14, pp. 745-769). Cambridge, MA: MIT Press.

Rosenbaum, D. A. (1980). Human movement initiation: Specification of arm, direction, and extent. Journal of Experimental Psychology: General, 109, 444-474.

Rosenbaum, D. A. (1983). The movement precuing technique: Assumptions, applications, and extensions. In R. A. Magill (Ed.), Memory and control of action (pp. 231-274). Amsterdam: North-Holland.

Salthouse, T. A. (1988). Resource-reduction interpretations of cognitive aging. Developmental Review, 8, 238-272.

Schneider, W. X. (1995). VAM: A neuro-cognitive model for visual attention control of segmentation, object recognition, and spacebased motor action. Visual Cognition, 2, 331-375.

Shallice, T. (1988). From neuropsychology to mental structure. New York: Cambridge University Press.

Shaw, M. (1984). Division of attention among spatial locations. A fundamental difference between detection of letters and detection of luminance increments. In H. Bouma \& D. G. Bouwhuis (Eds.), Attention and performance (Vol. 10, pp. 109-120). Hillsdale, NJ: Erlbaum.

Shiffrin, R. M. (1988). Attention. In R. C. Atkinson, R. J. Hermstein, G. Lindzey, \& R. D. Luce (Eds.), Stevens' handbook of experimental psychology (pp. 739-811). New York: Wiley.

Shiu, L., \& Pashler, H. (1994). Negligible effect of spatial precuing on identification of single digits. Journal of Experimental Psychology: Human Perception and Performance, 20, 10371054. 
Sperling, G. (1984). A unified theory of attention and signal detection. In R. Parasuraman \& D. R. Davies (Eds.), Varieties of attention (pp. 103-181). London: Academic Press.

Sperling, G., \& Dosher, B. A. (1986). Strategy and optimization in human information processing. In K. Boff, L. Kaufman, \& J. P. Thomas (Eds.), Handbook of perception and performance (Vol. 1, pp. 2.1-2.65). New York: Wiley.

Spieler, D. H., Balota, D. A., \& Faust, M. E. (1996). Stroop performance in healthy younger and older adults and in individuals with dementia of the Alzheimer's type. Journal of Experimental Psychology: Human Perception and Performance, 22, 461479.

Teeken, J. C., Adam, J. J., Paas, F. G. W. C., van Boxtel, M. P. J., Houx, P. J., \& Jolles, J. (1996). Effects of age and gender on discrete and reciprocal aiming movements. Psychology and Aging, 11, 195-198.

Tellinghuisen, D. J., Zimba, L. D., \& Robin, D. A. (1996). Endogenous visuospatial precuing effects as a function of age and task demands. Perception \& Psychophysics, 58, 947-958.
Umiltá, C., \& Nicoletti, R. (1990). Spatial stimulus-response compatibility. In R. W. Proctor \& T. G. Reeve (Eds.), Stimulusresponse compatibility (pp. 89-116). Amsterdam: NorthHolland.

van der Heijden, A. H. C., \& Eerland, E. (1973). The effects of cueing in a visual signal detection task. Quarterly Journal of Experimental Psychology, 25, 496-503.

van der Heijden, A. H. C., Schreuder, R., \& Wolters, G. (1985). Enhancing single-item recognition accuracy by cueing spatial locations in vision. Quarterly Journal of Experimental Psychology Section A: Human Experimental Psychology, 37A, 427-434.

Welford, A. T. (1980). Relationships between reaction time and fatigue, stress, age, and sex. In A. T. Welford (Ed.), Reaction times (pp. 321-354), London: Academic Press.

Received September 5, 1995

Revision received February 24, 1997

Accepted April 2, 1997 